\title{
La Ciudad de Dios desde la perspectiva de la razón: la cuarta politeia de la antigüedad ${ }^{1}$
}

\author{
Óscar Velásquez. \\ UNIVERSIDAD DE CHILE
}

Del origen, desarrollo y maduración de una idea fundamental en Occidente, ese es el tema sobre el que intento reflexionar aquí, tomando como núcleo central algunas de las relaciones que existen entre politeia, res publica y cimitas en cuatro grandes obras, a saber, República de Platón, Política de Aristóteles, República de Cicerón y Ciudad de Dios de san Agustín. Es una historia que pone a Platón, Aristóteles, Cicerón, Agustín en el plano único de la compleja historia del traspaso de una temática de orden político y moral en su inicio, religiosa finalmente, en que las variantes y diferentes énfasis que se presentan en cada caso, añaden mayor interés al tema en general. Pero esta historia no puede ser contada sino apenas esbozada aquí -y además muy parcialmente-, si bien espero decir cómo se ven, desde la perspectiva de la Ciudad de Dios de san Agustín, esos posibles nexos y correspondencias con el resto, esas divergencias y semejanzas, en fin, las peculiares características de lo que llamo estado de maduración en el pensamiento de Agustín, al interior de una era dominada por la polis griega y el imperio romano. De ahí que hablo de antigüedad (sea ella alta o baja) y de una cuarta politeia; y si bien madurez no es necesariamente perfección en el sentido aristotélico, sí podemos considerar que se relaciona con el estado en que una idea adquiere su pleno desarrollo al interior de una amplia etapa histórica, como es la que llamamos antigüedad; y la Ciudad de Dios parece ser un centro de convergencias del vasto desenvolvimiento histórico de una concepción de ciudad, que a mi juicio culmina con el fin de la

1 Este trabajo forma parte del proyecto Fondecyt 1085030, «Politeia, respublica, cinitas: permanencia y metamorfosis de una idea en las cuatro grandes repúblicas de la Antigüedad». 
antigüedad en las cercanías de la caída del imperio romano de Occidente. Mi estudio está, en consecuencia, particularmente interesado en analizar la obra Ciudad de Dios como inserta en una tradición poderosa, en que Cicerón ocupa un lugar privilegiado de enlace con el pensamiento griego, y donde, si se quiere, el último eslabón histórico en la baja antigüedad es san Agustín ${ }^{2}$. Cuatro politeiai, cuatro mundos en situaciones análogas aunque diferentes y críticas cada cual, con maneras distintas de enfrentar los problemas y plantear las soluciones; pero, al fin, cuatro modos curiosamente conectados como en forma ineluctable con temáticas genialmente iniciadas en la Politeia de Platón. Esto significa, sin duda, dejar aquí en una cierta penumbra muchos aspectos más originalmente cristianos y teológicos, que inciden más directamente en el significado propio del De ciuitate Dei, y que han sido discutidos incansablemente por numerosos autores $^{3}$. Sin pretender, entonces, hacer una síntesis en esta presentación, evidentemente incompleta y parcial, de toda la vasta malla de confluencias culturales que se concitan en esta inmensa obra, mi objetivo consciente es discriminar en la elección de los temas con el propósito de resaltar niveles de comprensión más propiamente relacionados con el diseño de la Ciudad de Dios, los que son más bien tributarios (consciente o inconscientemente) de toda una tradición que vincula esta obra al conjunto de los

2 Sin tomar en consideración necesariamente la Ciudad de Dios, el De Republica es la obra de Cicerón más mencionada por san Agustín en sus escritos. Pero, como dice Hagendahl, «The vast majority concern two writings: 44 De civitate Dei and 7 Contra Iulianum»: H. Hagendahl, Augustine and the Latin Classics, II (Studia Graeca et Latina Gothoburgentia XX; Göteborg y Uppsala 1967) 542; cf. 540-553). J. G. PowelL suma en 36 los testimonia de la República de Cicerón en la Ciudad de Dios, en J. G. Powell, M. Tulli Ciceronis De Re Publica (Oxford 2006) 371-372.

3 Ya en el Congreso Agustiniano de París 1954, Joseph Ratzinger establecía sus argumentos sobre el origen y significado de las enseñanzas de san Agustín en la Ciudad de Dios frente a Wilhelm Kamlah. Ratzinger daba el nombre de pneumatisch-ekekesiologische o también de sakramental-ekklesiologische a esas enseñanzas del Hiponense en, J. Ratzinger, «Herkunft und Sinn der Civitas-Lehre Augustins: Begegnung und Auseinandersetzung mit Wilhem Kamlah», Augustinus Magister. Congrès International Augustinien. Communications (Paris, 1954) 965-979. Me interesa destacar el acuerdo que manifiesta con un aspecto del pensamiento de Kamlah, a saber, que las enseñanzas de Agustín en la Civitas Dei no son una construcción subversiva o revolucionaria («eine umwälzende Konstruction»), sino que se relaciona con el antiguo kerigma. El puesto de la Ciudad de Dios entre las repúblicas, digo yo desde el punto de vista de una visión moral y política, coloca a san Agustín también en una línea de pensamiento que lo sitúa asimismo al interior de una larga y antigua tradición grecorromana. 
modelos que la precedieron ${ }^{4}$. Porque en relación con la idea misma de una ciudad celeste, es claro que corresponde a un contexto ya conocido por sus contemporáneos, de modo que san Agustín nos habla mucho de ella sin precisamente definirla: «En parte es así porque el concepto es familiar y tradicional» ${ }^{5}$; y la consistencia de la obra junto a su atractivo está sobre todo en su poder de concitar todo un mundo de reflexiones y antecedentes en torno a esa gran idea de carácter teológico llamada ciudad o reino de Dios. Ahora bien, por tratarse además de una ciuitas, sus antecedentes naturales $-y$ esto es aquí un punto principal- están asimismo íntimamente presentes como una vivencia de carácter moral y político en la cultura grecorromana. El análisis de esto y de otras cuestiones lleva consigo un tema que aquí es solo esbozado, es decir, el de la Iglesia como una isopoliteia, que representa el goce de la igualdad de derechos cívicos de quienes pertenecen a la ciudad celeste como institución eclesiástica de carácter jurídico ${ }^{6}$.

Mi estudio, entonces, es sobre un diseño, es decir, de cómo se estructura un proyecto en el devenir de la obra, y de qué modo el autor logra realizar el trazado de su plan. La consideración que es posible hacer sobre la existencia de una planificación de vasto alcance en la Ciudad de Dios-que

4 É. Gilson, Las metamorfosis de la Ciudad de Dios (Buenos Aires 1954) emprende la tarea de revisar la historia posterior a San Agustín sobre esta idea en un libro memorable; y esa historia comienza dramáticamente: «Hermosa es la esperanza», dice, «pero el imperio romano iba a perecer en el preciso momento en que los cristianos pensaban utilizarlo [...] Así, por vez primera, un imperio se desmoronaba en el momento mismo en que la Iglesia abrigaba la esperanza de apoyarse en él» (p. 40).

5 F. E. Cranz, «De Civitate Dei, XV, 2, and Augustine's Idea of the Christian Society», Speculum 25 (1950) 215. Así como el trabajo de Cranz lo lleva a establecer relaciones con una sociedad cristiana, una Jerusalén celeste, y con los conceptos de reino celestial y ecclesia, así nuestra investigación, a su vez, busca hacer presente las conexiones de esta societas con las grandes otras sociedades o repúblicas que la han precedido. En el caso de este artículo citado, es que, a diferencia de grandes escritores como Eusebio, «el imperio romano y la ecclesia cristiana no están esencialmente conectados» (F. E. Cranz, «De Civitate Dei, XV, 2, and Augustine's Idea of the Christian Society», 220).

6 La isopoliteia, un término ya usado por Aristóteles, según mi saber no está presente en san Agustín, pero sí su temática permanente en torno a las relaciones de la ciudad celeste y el imperio. Un valioso artículo, en especial sobre aspectos jurídicos y sociales relativos al concepto ciudad de Dios en autores anteriores o justamente contemporáneos de Agustín, da importantes pistas sobre estos aspectos más directamente constitucionales e históricos: K. F. MORrison, «Rome and the City of God: An Essay on the Constitutional Relationships of Empire and Church in the Fourth Century», Transactions of the American Philosophical Society, 54-1 (1964) 3-55. 
indudablemente es preconcebida- se manifiesta claramente fundamental para llevar a cabo la obra y así dirigirla y encauzarla con un objetivo de unidad; y a juzgar de la amplitud alcanzada por las repúblicas anteriores, nos hallamos ante un cierto modelo de reflexión que parece exigir una extensión poco común. El enfoque sobre el diseño es el que me permite, además, hacer manifiestas de un modo más explícito los numerosos nexos que se pueden establecer entre estas cuatro obras. Dividiré, en consecuencia, mi presentación, para examinar en cada caso brevemente aquellos aspectos que considero relevantes en esta búsqueda de relaciones.

\section{La ciudad ideal}

Hay una tradición que se remonta a Platón: la ciudad ideal tiene su paradigma en el cielo (en ouranō); y un aspecto interesante es que ese modelo ejemplar está allí «para quien quiera contemplarlo, y al contemplarlo, fundar la ciudad en sí mismo» (kai horōnti beautón katoikidsein, R. 592b) ${ }^{7}$. La ciudad celeste de Platón se realiza en esta vida, específicamente, al interior de quien se dispone a verla; y se hace manifiesta más precisamente en ese acto de fundación que tiene lugar en el alma. Hay así dos planos que buscan integrarse, el de allá en la Idea, el de acá en el interior de un ser virtuoso. La ciudad ideal o la mejor (peri politeias arístes, VII 1323 ${ }^{\mathrm{a}} 14$ ), es también lo que se busca en la Política de Aristóteles, cosa que va precedida sugestivamente de la investigación de cuál es la vida más deseable (tís hairetōtatos bios, VII 1323a 16). Politeia y bios van así a la par, en dos dimensiones que se expresan a su vez tanto en el individuo como en la sociedad. En Cicerón el asunto se da en un plano más complejo aunque perfectamente compatible con este esquema, pues el tema fundamental es precisamente de optimo cinitatis statu (Resp. I 70). La politeia es ahora ciuitas, y la ciuitas, a vez, respublica. En efecto, Escipión afirma su convencimiento de que «ninguna de todas las repúblicas, sea por su organización o por su planificación, es comparable con la que nuestros padres dejaron consolidada para nosotros» (nobis acceptam... reliquerunt). De este modo, el objetivo central de la obra es mostrar «en forma simultánea el carácter de esta constitución, y porqué es la mejor»: en esas circunstancias, la república romana de los tiempos anteriores a la revolución gracana, es decir, hacia el 129 a. C., se transforma en paradigma, exemplum, para toda otra

Cf. J. Adam. The Republic of Plato II (Cambridge $\left.{ }^{2} 1965\right) 370$ n. 8. El beautón katoikidsein revela un aspecto de intimidad moral, que en la cinitas celeste de san Agustín ha de adquirir un valor más específicamente religioso. 
concreta realización anterior o posterior. La república ideal ya fue -etsi ne nunc quidem ${ }^{8}$, es decir, «aunque en ningún caso ahora»-, y en este contexto nos podemos preguntar, si Cicerón no está siguiendo también aquí a Platón con la idea presentada en el Timeo (libro que él mismo tradujo al latín en una parte importante, y que Platón consideraba una continuación de su república), de que en antiguos tiempos existió una Atenas ideal que desapareció en un tremendo seísmo, contemporáneo con el cataclismo que destruyó la Atlántida. El modelo se oculta en una historia -remota en este caso- que hay que rehacer, cosa que Platón dejó inconclusa en el Critias, por razones que no se pueden contar ahora'. Así, entonces, parte importante del análisis de la República de Cicerón se transforma en un examen de la historia de Roma a partir del libro II, de un modo semejante a como Agustín lo hace entre los libros XV hasta el XVIII, y, de un modo general, a partir del XI hasta el final de la obra, en que se pasa revista a ambas ciudades. Hay un progreso en la historia sacra hacia Cristo en su encarnación y segunda venida (donde diversos actores anteriores, como Moisés o Abraham van consolidando un devenir histórico), de una manera que recuerda a Cicerón, en que «nuestra república, dice, no se habría consolidado con el talento de uno solo sino de muchos, ni en una sola generación sino a lo largo de algunos siglos y períodos de vida humana» ${ }^{10}$. Mas el paralelo con Cicerón es aun mayor si tomamos en consideración que, en san Agustín, ese proceso de afianzamiento se hace realidad desde un antiguo testamento que prefigura el nuevo:

«Esta casa de Dios», dice, «es de una gloria mayor a esa primera que había sido construida de maderas y piedras y otros materiales preciosos y minerales [...] Pues esta casa que pertenece a la nueva alianza es tanto de mayor gloria cuanto mejores son las piedras vivas con las que se va edificando de creyentes y renovados» (Ciu. XVIII 43).

De ahí que, cual resultado del modo como la relación de Cicerón sobre la res publica alcanza su culminación en el modelo de constitución de la primera República, así, «In a sense, Agustine’s account of institutions

\footnotetext{
8 M. T. Cicerón, Respublica I, 71.

9 He discutido ese tema en O. VeLÁsquez, «Dificultades epistemológicas en el discurso de Critias», Diadokhé (2004-2005) 141-155.

10 M. T. Cicerón, Respublica II, 2. Cf. G. J. P. O’Daly, «Thinking through History: Augustinian Method in the City of God and Its Ciceronian Dimension», Augustinian Studies 30-2 (1999) 54 ss.
} 
climaxes in the establishment of the Christian church (Ciu. 18, 48-53)» ${ }^{11}$. Se podría decir que esta progresión desde la antigua hacia la nueva alianza tiene en Cicerón un proceso paralelo con el desarrollo gradual que alcanza su apogeo en la primera República.

La diferencia en Agustín, es que debe realizar el recuento de una historia paralela, la sacra y la terrena, porque las cinitates son dos. Por otra parte, hay un sentido de objetivo en esta historia, en que Escipión, como lo hará San Agustín a lo largo de la Ciudad de Dios, piensa conseguir mejor su propósito «si et nascentem et crescentem et adultam et iam firmam atque robustam ostendero ${ }^{12}$ : claro que, esta afirmación ciceroniana indica además, que preferirá este método al de Platón, que inventa la suya propia (ipse finxero), y hace de su calipolis una propuesta para el futuro. Ya la historia se había introducido en la Política de Aristóteles, aunque parece tener más un papel de refuerzo en la argumentación que formar parte central de ella.

En Cicerón, a su vez, es parte central de su argumentación el demostrar que la república romana ha madurado con el paso de los siglos, cosa que utiliza para distanciarse además de Platón y del resto de los sabios de Grecia, que discurrieron sobre los géneros y los regímenes de las ciudades (cinitatum) «sin ningún ejemplar y forma explícita de república» («sine ullo certo exemplari formaque reipublicae»)..$^{13}$ Esto no es totalmente cierto de Platón, que afirma que si bien su república no existiría en lugar alguno de la tierra, reside en el cielo un paradigma de la ciudad para quien la quiera ver y fundar una para una sí (Rep. IX 592a-b). Aunque el mismo Platón le daría cierta razón a Cicerón, si hemos de considerar lo que dice en el Timeo sobre su propia república: la ve allí como si contemplara seres vivos y hermosos, pero como «en pintura»o «en reposo» ${ }^{14}$. El paso del romano a lo concreto le exige recurrir a la historia, una decisión que, de un modo cierto ha de perdurar en Agustín, ciudadano romano al fin. Este es uno de los grandes temas de la ciencia política, a saber, el nexo entre la teoría y la acción. Cicerón muestra a Escipión exponiendo su historia: «no me-

11 G. J. P. O'DALY, «Thinking through History: Augustine’s Method in the City of God and its Ciceronian Dimension», 57. Esta progresión desde la antigua hacia la nueva alianza tiene en Cicerón un proceso paralelo con el desarrollo gradual que alcanza su apogeo en la primera República.

12 M. T. Cicerón, Respublica II, 3.

13 M. T. Cicerón, Respublica II, 22.

14 Platón, Tim. 19b. 
diante un discurso errático sino fijo en una sola república» ${ }^{15}$. Cicerón está convencido que ha encontrado el modelo. Lo que persigue el orador se hace evidente de inmediato: el objetivo es mostrar la república como si ella hubiese alcanzado su perfección. Esta progresión desde la antigua hacia la nueva alianza tiene en Cicerón un proceso paralelo con el desarrollo gradual que alcanza su apogeo en la primera República («quasi perfectam rempublicam»).

Se hace perceptible aquí una conciencia del progreso gradual de la historia del hombre, que en Agustín se ha de mostrar como la expresión de los dos amores que hacen a cada una de las dos ciudades ${ }^{16}$. Y olvidando un tanto la parte polémica de Agustín contra Cicerón, por causa de su negación de la presciencia divina de las cosas futuras, queda perfectamente en claro que el romano se decide igualmente por el libre albedrío de la volun$\operatorname{tad}^{17}$ : por tanto, niega la necesidad histórica y adhiere a una concepción del deseo (uoluntas) como causa de las acciones del hombre en el devenir de los tiempos. Que la voluntad hace historia, es, en consecuencia, una doctrina que acerca a ambos pensadores, y los coloca en una cierta armonía con sus antecesores griegos. Pero sea de dónde hayan obtenido los romanos el impulso para entender la primacía de la voluntad en el hacer de la historia, parece claro que, tanto Salustio como Cicerón, fueron más allá de los griegos en confirmar la capacidad del libre albedrío humano en su poder de decisión sobre los acontecimientos del mundo. Pero es Agustín el que perfila esa historia con su famosa teoría de los dos amores. Porque el amor (sea trascendente o inmanente, celestial o terrenal) se transforma en el motor de la historia.

De ahí que, en el pensamiento de Agustín, hay dos amores que conforman el núcleo de dos tipos de humanidad, los que se polarizan en Dios o en el hombre, y esta humanidad tiene un devenir histórico con un excursus o avance, como si fuera el itinerario de la humanidad. Es un progreso donde la historia corre ahora paralela, con dos cimitates que se entremezclan. Hay un ab initio usque ad finem de estas dos ciudades, que avanzan mezcladas en el siglo (permixtarum); un fluir que avanza como una corriente, es decir, hay un cursus, de esta historia, en que la ciudad celeste peregrinatur in terra «hasta que se separen en el último juicio y alcance cada

15 Platón, Tim. 19b.

16 Agustín, De Cinitate Dei XIV, 28.

17 Agustín, Ciu. V 9, 1. 
cual su fin, del que no hay fin» ${ }^{18}$. Esta conclusión de carácter cívico es un acontecimiento escatológico de tipo planetario, y le da a la visión cristiana de la Ciudad de Dios un rasgo dramático de intencionalidad histórica que hallamos también expresado, si bien de una manera individual, en el mito de Er y el Sueño de Escipión. En la mentalidad de Agustín, que trabaja con antítesis, la descripción del acontecer de la ciudad celeste en la tierra es acorde con el relato del devenir de la ciudad terrestre: ambas son ciuitates, ambas tienen un populus, ambas aman sus objetos y supremo bien, y una y otra busca la gloria en lo que ama. En fin, ambas avanzan en los tiempos, una pretendiendo permanecer en él, y la otra como el pueblo escogido a través del desierto. Y como la verdadera historia es colectiva y social, el sentido agustiniano del transcurso temporal adquiere esa calidad si se quiere moderna que lo distingue de sus predecesores.

De ahí que junto al excursus o desarrollo, que es el movimiento fluyente de estas ciudades ${ }^{19}$, se hable también de su exortus, es decir, surgimiento, aparición. Las ciudades se ven en su configuración temporal, en el devenir de una historia que les proporciona un futuro. Unas generaciones serán reemplazadas por otras, pero hay un momento en que «los hombres cesarán de generar $\rangle^{20}$. Y la historia de estas ciudades comprende todo ese lapso de tiempo (uniuersum tempus sive saeculum) en que las generaciones humanas se suceden.

\section{La decadencia}

Séame permitido teorizar primero. La acusación pagana de que los tiempos cristianos han traído la ruina al imperio romano, se sostiene en la percepción de un estado mejor de cosas anterior, que se asemeja a la visión ciceroniana. Una decadencia de la sociedad es solo concebible aquí en la perspectiva de la ideología de una res publica o una cinitas ejemplar que deviene en peor; en otras palabras, de una república cuyo avance de progreso y crecimiento en el decurso del tiempo se ve impedido por un

18 Agustín, Ciu. XVIII 54, 2. Cf. Ciu. Prólogo, en que se hacen manifiestos los dos planos en que se mueve la ciudad de Dios, in hoc temporum cursu, es decir, «en el transcurso actual de los tiempos». Estos planos son su peregrinación presente entre los impíos viviendo de la fe, y su permanencia futura en la estabilidad de su eterna sede.

19 Agustín, Ciu. XV 1: «Nunc autem quoniam de exortu earum [...] iam mibi uidetur earum aggrediendus excursus ex quo ille duo generare coeperunt donec homines generare cessabunt».

20 Agustín, Ciu. XV 1: «cessabunt». 
factor que es necesario esclarecer, y si es preciso, extirpar. Los paganos de la época de Agustín dirán que la república romana ha sido arruinada por el cristianismo. Por otra parte, la idea de decadencia está claramente examinada en la República de Platón en su famoso texto de los cuatro tipos de regímenes en el libro VIII, que no contiene una visión historicista del devenir como lo pretende anacrónicamente Popper, sino una de carácter fundamentalmente psicológico: son tipos de seres humanos que dan forma a tipos de gobierno, cuyos cambios de una generación a otra son producidos por transformaciones en la psicología y la conducta de padres e hijos al interior de la sociedad. El deterioro de la sociedad no es visto todavía como un concepto histórico sino fundamentalmente moral. En Platón hallamos un bosquejo de cómo podrían funcionar los cambios en una sociedad, no un recuento histórico de ellos, ni de la necesidad de su realización. Para eso se precisa una teoría de la historia, cosa que Platón no parece tener, porque la circularidad de su concepción del tiempo se lo impide, aunque anduvo cerca; como tampoco la posee Aristóteles, que se contenta con sus dotes de historiógrafo. Platón anduvo cerca porque concibió el tiempo como imagen de un aiōn, es decir, como imitación móvil de una vida eterna; una vida imitación de eternidad que es astronómica, física e inteligible. No es quizá simplemente física, sino bío-física, pues se confunde con el alma del mundo, que es una entidad matemática viviente. A Aristóteles le interesa establecer la calidad de los intervalos, y no se aleja mucho de Platón al suponer que el tiempo no es fundamentalmente movimiento, sino número del movimiento con respecto al antes y al después. Ahora bien, si nos encontramos con que solo el movimiento en círculo es el verdaderamente uniforme, y si queremos además utilizar este concepto de tiempo para concebir la historia, corremos el riesgo cierto de transformarla en circular. Y si es así, le quitamos un objetivo lineal. Les falta a ambos, entonces, una noción del tiempo como realidad humana y social en marcha, irrepetible, única en su realización, que no es solamente física sino que está provista de la concepción de un progreso sujeto a leyes, donde las organizaciones cívicas poseen estructuras con un dinamismo propio y una cualidad de características biológicas, que hacen posible medir avances y retrocesos o establecer períodos de progreso y decadencia como un fenómeno universal, y no simplemente local o individual. En otras palabras, medir los progresos y decadencias del mundo mediante parámetros verdaderamente históricos. 
Los griegos conocían y temían esos cambios y destrucciones que se manifestaban en las poleis, esas staseis de todo tipo, que minaban la confianza de los ciudadanos en la perduración de las instituciones políticas. Faltaba perfeccionar, sin embargo, el conocimiento de los mecanismos que relacionaban al individuo con la sociedad, su libertad, y la capacidad que el libre albedrío y el deseo humano poseen de cambiar el mundo en que se está. Mas para Agustín el verdadero problema para dar sentido a la historia está precisamente ahí, en ese no determinado deseo o voluntad humana, de modo que «no es completamente claro cómo, a pesar de su radical contingencia, los actos humanos son usados por Dios con fines para los que no han sido intrínsecamente ordenados»: porque se sigue de aquí que «el curso futuro de la historia es totalmente impredecible» ${ }^{21}$. El fin, entonces, de la experiencia humana sobre la Tierra «ha de terminar en el tiempo señalado, no por algo que los seres humanos han hecho o pueden todavía hacer, sino porque la voluntad de Dios ha decidido ponerle término» ${ }^{22}$. Esto no es teoría de la historia en el sentido moderno, sino quizá una teología, según que, como se ha señalado, el principio unificador del decurso de los tiempos proviene de la Revelación: de ahí la «enérgica insistencia» de Ratzinger (señalada por nuestro autor citado) de la «dimensión propiamente eclesial y sacramental del pensamiento de Agustín» ${ }^{23}$.

El asunto de la libertad es un problema real en la República de Platón, pero no lo veo relacionado con la historia. Esto sí se hace manifiesto en Cicerón: la historia es ahora un concepto tributario de una política, la que a su vez subsiste en íntima relación con la moral. Así entonces, esa historia es una historia de la evolución del hombre viviendo en sociedades cívicamente organizadas: estas son un coetus cinium, es decir, una sociedad de ciudadanos. He aquí la historia de una res publica, de una ciuitas. Y en Cicerón es, específicamente, la relación en términos de apariencia biológica del surgimiento, el apogeo y decadencia de una ciudad-estado más, como Roma, pero que alcanza posteriormente una condición imperial. $\mathrm{El}$ orador no es un historiador, pero entiende en este sentido como los

21 E. Fortin, «Augustine's "City of God" and the Modern Historical Consciousness», The Review of Politics 41 (1979) 327-328.

22 E. Fortin, «Augustine's "City of God" and the Modern Historical Consciousness», 327-328.

23 Según señala E. Fortin en el artículo citado, donde alude a J. RATZinger en «Volk und Haus Gottes in Augustins Lehre von der Kirche» (Munich, 1954) $=$ «Herkunft und Sinn der Civitas-Lehre Augustins», Augustinus Magister 2 (París, 1954) 965-979. 
griegos la historia cual registro de investigación, narración escrita de sucesos del pasado, y el conocimiento documentado de los eventos pasados. Porque no hay una diferencia substancial entre Roma y las ciudades estado griegas, si no es por la magnitud de su éxito; pero es precisamente ese éxito el que impulsa a Cicerón a considerarla un paradigma, realidad que Platón no encontró en su tiempo y tuvo que inventarla para el futuro. De ese modo Cicerón, al hallar un paradigma real en la historia de su pueblo romano, propone una ciudad del pasado cual modelo del futuro. Platón intentó crear con la Atlántida una historia mítica de alcances semejantes, pero el proyecto, iniciado en el Timeo, es abandonado en el inconcluso Critias. La ciudad de Dios, por su parte, representa la idea de una sociedad universal que escapa a los límites del espacio y el tiempo, pero que vive de todas maneras en el espacio y el tiempo secular, que vive en las almas de los individuos, donde tiene también su propia historia; pero debe además convivir con la ciudad terrena no solo en el plano individual sino también como un reino de carácter espiritual.

Tengo para mí, entonces, que la consciencia de un ocaso en el terreno de la politeia es una de las razones principales que mueven a Platón, Aristóteles y Cicerón a plantear sus propias repúblicas. Mas para los griegos, decadencia parece ser un concepto más político que histórico, más moral que teológico: como la stasis o disentimiento, facción, es un signo de la crisis de una ciudad. Por otra parte, Salustio es sobremanera importante, pero él no tiene la intención de abordar el tema en sí mismo sino de un modo monográfico en la figura de Catilina y de su tiempo. Su influencia, sin embargo, será enorme en Agustín al momento de hacer frente a las quejas del paganismo sobre las causas del decaimiento del Imperio ${ }^{24}$.

Ahora bien, la obra Ciudad de Dios surge como una defensa en contra de quienes sindican a los tiempos cristianos como los culpables del derrumbamiento del Imperio ${ }^{25}$. Lo que hace la diferencia entre Agustín y el resto de sus honorables predecesores es, en primer lugar, su comprensión del tiempo como expresión de la vida del espíritu, un tiempo que puede vivir en concordancia con la presencia de la eternidad divina en el alma. Se trata de una realidad que filosóficamente se ha llamado también un tiem-

24 Sobre todo en Ciu. V.

25 Buscaremos vanamente en libros de más de quinientas páginas como La idea de decadencia en la historia universal de A. Herman, no más de una mínima reflexión sobre nuestros autores antiguos, ya que consiste fundamentalmente en una interminable acumulación de información sobre los más diversos autores. 
po vivido por la consciencia: Ego, ego sum tempus. Para Agustín el tiempo es una dimensión espiritual («nihil esse aliud tempus quam distentionem», Conf. XI 33); él es por consiguiente una vivencia dimensional del espíritu, que podríamos llamar la duración de la consciencia, o el espacio del tiempo (una expresión extraordinaria que Agustín pronuncia como de pasada en Conf. XI 36) ${ }^{26}$. Esa dimensión es comprensible solo en su relación con la eternidad, desde la que esta misma, al modo de una extensión vital, es dimensión. Pero la eternidad es vida, y de ahí es posible visualizar la historia de un alma y su perpetua intencionalidad, que hacen de ella una continua marcha hacia el Dios que la hizo. Ahora bien, como si estuviera siguiendo los pasos de Platón, que para el estudio de la justicia recomienda pasar de las letras chicas al estudio de las letras grandes, que se refieren a la sociedad, así san Agustín completa en la Ciudad de Dios las letras grandes de la historia, luego de haber descrito las menores con la vida del alma en Confesiones. Esta es la transposición decisiva de lo individual a lo social: ahora, nos tempora sumus. El tiempo es vida acá y allá; y entendiendo ese tiempo como vida de la sociedad, me atrevo a pensar que esa es la historia de la que hablamos, es decir, el tiempo de la cinitas ${ }^{27}$. De ahí que se la nombre un temporum cursus, ${ }^{28}$ que indica un movimiento hacia delante, un paso, un progreso $^{29}$, por el que transcurre la vida de los hombres, y que, en el caso de la cinitas Dei, avanza hacia la estabilidad de la eterna morada ${ }^{30}$. Habría que insistir: el tiempo de la polis es la historia, una politeia que vive en el transcurso del tiempo. Mas se trata de una ciudadanía celeste, por tanto ese devenir tiene las características de un tiempo sacro, que ha de culminar en el «Sábado supremo» ${ }^{31}$.

\footnotetext{
26 Dicho aquí acerca de la determinación de los intervalos de silencio.

27 A. Mandouze, Saint Augustin L'aventure de la raison et de la grace (Études Augustiniennes; Paris 1968) 293, había expresado certeramente esta situación: «Cependant, qui touche à l'histoire ne saurait situer son effort indépendamment d'une certaine notion du temps. Une théologie ou une philosophie de l'histoire implique par là une conception théologique ou philosophique du temps. Le De cinitate Dei ne manque pas à la règle: le "temps humain" y est en quelque façon la transposition du temps personnel d'Augustin dans les Confessions». «siue in hoc temporum cursu cum inter impios peregrinatur ex fide uiuens», Agustín, Ciu. Prólogo.

Cf. M. T. Cicerón, Resp. I 64.

M. T. CiCERÓn, Resp. I 64.

31 Agustín, Ciu. XXII 30, 4: «Quod erit uere maximum Sabbatum non babens nesperam».
} 


\section{Justicia}

En la República de Platón la justicia no es un simple dar, pues hay siempre una relación con algo anterior: es al menos algo de dos. Un texto clave de esta dirección (Polemarco, República I): «es justo el devolver/retribuir (apodidónar) a cada uno lo debido (ta opheilómena)»; aunque Sócrates advierte el peligro si no se aclara el objeto de esa retribución ${ }^{32}$. Es análogo a kharin apodidónai (cf. Rep. 338b), dar gracias, pues uno da las gracias por algo anterior, de modo que es una suerte de retribución por, digamos, un bien recibido. Este elemento se encuentra en Agustín nuevamente (sospecho que no solo por intermediarios bíblicos) como un aspecto de la justicia cual virtud del justo. Ahora bien, la justicia platónica es, en resumidas cuentas, un hacer (poieîn, luego práttein), lo cual no quita que este hacer/ realizar tenga un cierto sentido de devolver. Estamos hablando sobre las letras grandes, es decir, de la justicia en la ciudad, en que el motivo superior de la justicia es la obtención de la unidad, y por tanto, la concordia en la ciudad. Si Platón habló así, no sorprende leer en la Política de Aristóteles (quizás pensando en Polemarco) que «la injusticia más dura es la que tiene armas» (Pol. I 2, $1253^{a}$ 33); pero además, que «la justicia es cosa de la ciudad, porque el derecho es el orden de la comunidad cívica»: hède dikaiosyne è politikón hègar dike épolitikèes koinō nías taxis (Pol. 1253a 37). Traduzco dikèe como derecho, es decir, en conexión con una regla, y equivalente a ius, así como iustus y iustitia en latín se relacionan con ius, el derecho. Este sentido cobra relevancia en Cicerón, en que el necesario uinculum incolumnitatis (vinculo de seguridad del estado) que permite una concordia en la ciuitas, es la iustitia (Resp. II 69).

Cave recordar nuevamente mi intención aquí, que consiste en reunir antecedentes que den cuenta de la creación, traspaso y continua elaboración de un plan, de un diseño en el gran tema politeia, respublica, cimitas, en que la controversia, señalada por el respeto entre los participantes de este exclusivo club de pensadores, es frecuente a partir de Aristóteles, puesto que todo parte de Platón. Esta temática común, a la luz de la autonomía evidente de cada autor, y de las circunstancias disímiles que a cada cual le toca enfrentar, hacen de este conjunto de cuatro politeiai uno de los testimonios más fascinantes de la perduración y maduración de una idea. Sabemos que Platón transforma a la Idea de justicia en la piedra angular

32 Pero de aquí, concluye Sócrates, se han sacado consecuencias erróneas, es decir, que eso de que (el justo) perjudica / hace daño (blabèn opheíleisthai), a los enemigos y be-

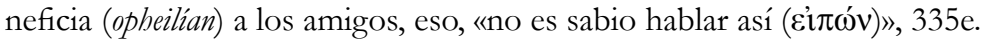


de su obra, dando paso así a un sujeto que será inseparable de la reflexión sobre la politeia. La Política no puede estar ausente de esta temática, que aparece a menudo en el examen de los tipos de gobierno, su relativa calidad y el carácter de su comunidad, como en Política II, 9. En otras palabras, su investigación está en estrecha conexión, como debería ser desde un punto de vista platónico, con el análisis de qué es una politeia, pues la justicia, dice, «es una virtud comunitaria a la que acompañan necesariamente las demás» $\left(1283^{a} 39\right)^{33}$. Esta condición de la justicia lleva consigo la forzosa consecuencia de que, siendo la justicia una virtud de carácter social (por mucho que toda virtud es asimismo personal), ella no puede existir sin los individuos que componen ese tejido. Virtud y politeia forman una unidad indisoluble. San Agustín habrá de argumentar en la Ciudad de Dios contra los que atacan a la religión cristiana, ya que justamente la ausencia de virtud había destruido tempranamente la república romana. Si no hay virtud, tampoco hay república.

Así, entonces, siendo la justicia tan esencial en la clarificación del concepto de politeia-cuitas-respublica, es natural que San Agustín, al enfrentar la acusación de que la destrucción de la cinitas romana se debe a los cristianos, recurra al análisis de aquello que constituye el fundamento mismo de ella, es decir, a la justicia como la virtud cardinal superior. En otras palabras, los análisis de Salustio, y en especial de Cicerón, como portavoz autorizado de la idea de respublica para la civilización romana, demostrarían que, si no hay justicia, no hay república; y eso es lo que ha sucedido con el régimen romano desde antes de la instauración misma del imperio. Y si toda res publica es una res populi, este pueblo también ha dejado de existir. ¿De qué se quejan ahora? Aparte del paso de Ciudad de Dios IV 4, que se pudo haber analizado aquí, es preciso examinar II 21, donde Agustín sigue estrechamente a Cicerón, que ha manifestado que debería haber una armonía entre las partes de la ciudad, llamada

33 En esta relación entre individuo y sociedad -fuertemente sostenida por la virtud de la justicia- san Agustín sigue también una línea de pensamiento que, como vemos, proviene de Platón. Como afirma G. O’Daly: «What of the Greek philosophical tradition? Augustine is aware of the purport of Plato's Republic "Or should the prize rather be awarded to Plato the Greek, who, when he was forming his ideal of what a state should be like, judged the poets should be expelled from the city as enemies of truth?" (City 2. 14). Like Plato, Augustine thinks of individuals and states as analogous (City 4. 3, 12. 28). But Augustine's model city is not, as Plato is, a paradigm for actual political states, which might be its image (Republic 592b; cf. 500e)»: G. O’DALY, Augustine's City of God (Oxford 2004) 59. 
concordia, y que sin justicia no hay concordia, y sin ella no hay república (II 69). Pero sobre todo, «no hay modo de conducir una república sin la supremacía de la justicia», dice (II 70). La fuerte respuesta de Agustín, utilizando los análisis de Cicerón como arma en contra de las quejas paganas del presente, es que «nunca hubo tal república, porque nunca hubo en ella verdadera justicia». Me interesa este texto, porque aquí, como en pocos momentos de una tan extensa obra como la Ciudad de Dios, se muestran dos aspectos fundamentales que he deseado mostrar a lo largo de todo este trabajo. En primer lugar, que Agustín es consciente de que su obra corre en paralelo con la de Cicerón, y que su respuesta al paganismo de su tiempo pasa a través de un análisis de esa República ${ }^{34}$; y luego, que, al modo como Cicerón se mide con Platón proponiendo una nueva ciudad ejemplar, la república romana de sus ancestros, así él, en su tarea de «defender la gloriosísima ciudad de Dios contra aquellos que prefieren sus dioses a su Fundador» (Prólogo), planifica su labor diseñando laboriosamente el relevo: «Ahora bien, concluye, no hay verdadera justicia sino en aquella república cuyo fundador y gobernante es Cristo». No hay entonces verdadera justicia donde el culto del verdadero Dios es rechazado ${ }^{35}$. Eso habría de significar una reorganización masiva del concepto de justicia, y de ahí también de pueblo, del pueblo que ha de conformar, en este caso, la ciudad celeste.

34 En este diálogo tenso pero profundamente racional entre Agustín y Cicerón, una cosa queda en evidencia, de acuerdo con el bien elaborado análisis de S. Magnavacca, «La crítica de San Agustín a la noción ciceroniana de "república"», Patrística et Mediaevalia III (1982) 54: «De esta manera se ha vuelto más claro lo que suponemos fue el objetivo de San Agustín en esta polémica que, a la distancia, sostiene con Cicerón: no anular sino utilizar el concepto de república elaborado por el romano -concepto que no solo era prestigioso sino aún recordado nostálgicamente en una Roma quebrantada- para variar su significación profunda llevándola a un plan más alto [...]».

35 Esta relación entre Agustín, Cicerón y Roma es analizada por P. WheitMan, «Augustine's Political Philosophy» en E. Stump - N. Kretzmann (eds.), The Cambridge Companion to Augustine (Cambridge 2001) 241, quien afirma, refiriéndose a Ciu. 19. 24: «There he makes the traditional claim that justice prevails only where each is given his due. It therefore demands, he says, the worship of the true God. Since God was not worshiped in Rome, justice never prevailed there. Since it is granted all around that Rome is a society, it follows that Scipio's definition of a society must be wrong». 


\section{Escatología}

El mito de Er el armenio es el resultado de un análisis anterior en República $\mathrm{X}$, que concluye que, si no hay mal alguno propio del alma que la pueda destruir, ella es inmortal; y si el peor mal para ella es la injusticia, puesto que lo mejor en ella es la justicia, en la vida de ultratumba una y otra, según el caso, decidirán con su presencia la suerte futura de su elección de vida. La inmortalidad está, por consiguiente, en estrecha relación con ese más allá en que se toman resoluciones decisivas. Y luego se afirma que la otra vida es una visión de luz (phōs euthî), donde hay un lugar, es decir, un prado (ton leimôna, X 614d) de espectáculos de incomparable belleza (X 615). En medio de esa luz hay un eslabón del cielo. Así, las recompensas que recibe el justo en esta vida, son nada en comparación de los premios que le aguardan después de la muerte, «entre visiones de una belleza prodigiosa» (X 615a: theas amékhánous to kallos) en ese cielo. Esto es en esencia el mito de Er, una suerte de profecía escatológica, en que se anuncia al ciudadano de la ciudad ideal, el hombre justo, que es en el cielo donde culmina la vida como contemplación, y donde al injusto se le niegan estos premios. La política de Platón supone ciudadanos de almas inmortales, que aspiran a la virtud, y a una vida que trasciende la terrena: el filósofo deja abierto el camino a la concepción de una ciudad de mil años en el cielo, pero no lo analiza. A San Agustín está reservado hablar de la glorificación eterna del pueblo de Dios (Ciu. XX 18). De la República de Cicerón, lamentablemente conocida para nosotros en solo un tercio aproximadamente de su volumen, se conserva intacto el Sueño de Escipión, un finale exigido muy probablemente por requerimientos de diseño interno semejantes a los de Platón. En el Sueño se destaca al político y sabio: es una exigencia de la búsqueda de la ciudad ideal, en que sus mejores hijos, filósofos y estadistas, reciben sus recompensas. Y en el caso de la Ciudad de Dios corresponde, a mi juicio, a una elección consciente de Agustín, que busca dar eficacia al contenido apologético de su obra. Aunque ella también está escrita para los cristianos, su objetivo son los paganos. El lugar que contempla Escipión es, asimismo, un espacio de espléndida claridad elucens inter flammas (Resp. VI 20 [16]). En la obra de Agustín, como hay dos ciudades, hay dos finales: el infierno y el cielo. Son asimismo espacios, en que la teología se abre a una visión cosmológica de la realidad futura. El libro XXII, al concluir, como en las repúblicas antecedentes (con excepción de Aristóteles), se nos habla de los premios futuros, que serán semejantes a los de los ángeles, conciudadanos originarios de esta ciudad. 
Este consiste en una visión: «sicut ergo illi wident, ita et nos wisuri sumus: sed nondum ita videmus» (XXII 29, 2). Por supuesto, Agustín se fundamenta en el apóstol Pablo, (I Cor 13, 12) «vemos ahora por un espejo, en enigma, pero luego veremos cara a cara»; y Juan (I, 3, 2), «cuando Dios se habrá manifestado, nosotros seremos semejantes a él, porque le veremos tal cual es». Y, a nombre de la doctrina de la fe sobre la resurrección de los cuerpos, no duda en polemizar con los filósofos, insistiendo en cómo con nuestros ojos corporales veremos todo con «clarísima transparencia» (XXII, 29, 6). Hace ver Agustín, además, que ese cielo es un lugar, un ubi, la domus del Señor, un ibi, es decir, «allí» («uera ibi gloria erit» (XXII 30, en que gloria tiene ese sentido de doxa, como lo que aparece, se manifiesta), y donde Dios mismo será el premio de la virtud.

Si la Ciudad de Dios había de ser una obra que, al ser leída por los paganos fuera lo suficientemente persuasiva como apología del cristianismo en la situación de crisis de su tiempo, ella debía entrar en el terreno mismo en que el gran pensamiento político del paganismo grecorromano se había desarrollado tan brillantemente. Su análisis de la ciudad antigua, en especial de la romana, en que prácticamente disuelve los ataques del paganismo mediante el testimonio de los mismos grandes autores romanos, es de una solidez incomparable; y la aparición de una nueva república en el escenario de las tres anteriores, la Ciudad de Dios, trae consigo un inédito reordenamiento de la historia del hombre, que habrá de tener profundas repercusiones en la visión del mundo en occidente. 
Resumen: Este artículo reflexiona acerca de la relación entre los conceptos de politeia, res publica y civitas en cuatro grandes obras: República de Platón, Política de Aristóteles, República de Cicerón y Ciudad de Dios de san Agustín, poniendo especial atención en esta última, en la medida en que se inserta en una tradición en la que Cicerón ocupa un lugar privilegiado de enlace con el pensamiento griego, y que, en fin, tuvo profundas repercusiones en la visión de mundo en occidente.

Palabras clave: Agustín, Civitate Dei, res pública.

Abstract: This article reflects on the relationship between the concepts of politeia, res publica and civitas in four major works: The Republic by Plato, Politics by Aristotle, Republic by Cicero and City of God by Saint Augustine, with special attention on the latter, insofar as it is inserted in a tradition in which Cicero occupies a privileged position of a link with Greek thought, and which, in the end, had profound repercussions on the Western world view.

Key words: Augustine, Civitate Dei, res publica. 